\title{
Sexual dysfunction following surgery for rectal cancer: a single-institution experience
}

\author{
William R. G. Perry ${ }^{1}$ Mohamed A. Abd El Aziz ${ }^{1,2}$ (D) Emilie Duchalais $^{3} \cdot$ Fabian Grass $^{1,4} \cdot$ Kevin T. Behm $^{1}$. \\ Kellie L. Mathis ${ }^{1} \cdot$ Scott R. Kelley ${ }^{1}$
}

Received: 1 April 2021 / Accepted: 25 June 2021 / Published online: 8 July 2021

(C) Italian Society of Surgery (SIC) 2021

\begin{abstract}
Although much focus is placed on oncological outcomes for rectal cancer, it is important to assess quality of life after surgery of which sexual function is an important component. This study set about to describe the prevalence of sexual dysfunction by resection type and gender among patients undergoing surgery for rectal cancer, usingretrospective analysis. All Englishspeaking living patients who underwent surgery for stage I-III rectal cancer with curative intent between 2012 and 2016 were identified from a prospectively maintained database at our institution. Eligible patients were invited to complete either the Female Sexual Function Index (FSFI) or the International Index of Erectile Function (IIEF). Primary outcomes were overall rates of sexual dysfunction, defined as more than one standard deviation below the mean of the normal population for each tool. A total of 147 patients responded, yielding a response rate of 38\%. The overall sexual dysfunction rate was $70 \%$ at a median time from surgery of 38 months. Sixty-two men (62\%) and 41 women $(87 \%)$ reported overall scores that fell below one standard deviation of the population mean. There was no significant difference in sexual dysfunction for both male and female patients between low anterior resection, coloanal anastomosis, or abdominoperineal resection.. The present study revealed a high rate of sexual dysfunction after rectal cancer surgery, particularly in female patients. This study serves as a reminder to surgeons and their teams to openly discuss the impact of surgery on sexual function and ensure adequate consent and appropriate peri-operative management strategies. The retrospective nature of the analysis is the limitation of this study.
\end{abstract}

Keywords Sexual dysfunction $\cdot$ Colorectal cancer $\cdot$ Colorectal surgery $\cdot$ Functional outcomes

William R. G. Perry and Mohamed A. Abd El Aziz shared first authorship.

Scott R. Kelley

kelley.scott@mayo.edu

1 Division of Colon and Rectal Surgery, Department of Surgery, Mayo Clinic, 200 First Street SW, RochesterRochester, MN 55905, USA

2 Internal Medicine Department, Texas Tech University HSC El Paso/The Hospitals of Providence Transmountain Campus, 2000B Transmountain Road, Suite 400 I MSC 42001, El Paso, TX 79911, USA

3 Digestive and Endocrine Surgery Clinic (CCDE), Institute of Diseases of the Digestive System (IMAD), University Hospital Center of Nantes, 1, Place Alexis-Ricordeau, 44093 Nantes, France

4 Department of Visceral Surgery, Lausanne University Hospital CHUV, University of Lausanne, Lausanne, Switzerland

\section{Introduction}

Nearly 43,500 new cases of rectal cancer are diagnosed in the United States every year [1]. Much focus is placed on oncological outcomes; however, improvement in survival attention has turned to the quality of life.

Sexual function is an integral component of quality of life and wellbeing $[2,3]$ and can be greatly affected by surgery [4]. Sexual dysfunction is a common complication following surgery for rectal cancer [5] as either a direct result of anatomical or neural disruption or indirect result due to the presence of a stoma (altered cosmesis) or loss of continence.

The majority of studies to date have focused on male dysfunction or explored sexual dysfunction as a secondary outcome using non-standardized metrics [5]. Few have specifically looked at the difference between the type of resection and sexual dysfunction across both genders [5]. 
This study set about to describe the prevalence of sexual dysfunction by resection type and gender among patients undergoing surgery for rectal cancer.

\section{Methods}

\section{Study population}

All living patients who underwent surgery for rectal cancer with curative intent between 2012 and 2016 were identified from a prospectively maintained database at the Mayo Clinic in Rochester, Minnesota. Non-English speaking patients and those who had stage IV rectal cancer were excluded.

\section{Questionnaire}

Participants were invited by mail to complete a questionnaire. Patients who had not returned the survey within 1 month received a phone call and were provided the opportunity to complete the questionnaire over the phone. Patients were not contacted by phone more than two times. Female patients were asked to complete the Female Sexual Function Index (FSFI) [6], a 19-item validated tool containing 6 domains: desire, arousal, lubrication, orgasm, satisfaction, and pain. Male patients were asked to complete the International Index of Erectile Function (IIEF) [7], a 15-item validated tool containing five domains: erectile function, orgasmic function, sexual desire, intercourse satisfaction, and overall satisfaction.

\section{Surgery}

All patients underwent total mesorectal excision. Operations were defined as follows: a low anterior resection (LAR) when a portion of rectum below the peritoneal reflection was left for completion of a stapled anastomosis; a coloanal anastomosis (CAA) when an anastomosis was undertaken onto the anal canal; and an abdominoperineal resection (APR) when the rectum and anus were completely excised.

\section{Analysis}

Baseline demographics, perioperative risk factors, cancer staging, neoadjuvant treatment, and postoperative outcomes were compared across patients who had a LAR, CAA, or APR. Primary outcomes were overall rates of sexual dysfunction, defined as more than one standard deviation below the mean of the normal population for FSFI (less than 25.2) and IIEF (less than 42.9) [6,7]. The normal population, the control group in the original publication for the FSFI, included women who reported no problems with arousal, desire, or orgasm and were sexually active in a stable heterosexual relationship. For the IIEF, the control group for the original study included volunteers from outpatient community settings who were clinically judged by the primary investigator as having a normal erectile function. Secondary outcomes were rates of dysfunction for the six FSFI domains and five IIEF domains, once again defined to be abnormal if less than one standard deviation below the normal population means.

Continuous variables were summarized as median (interquartile range) and categorical variables were summarized as frequencies and percentages. Multi-group comparisons were evaluated using Chi-squared test for categorical variables and Kruskal Wallis test. An alpha level of less than 0.05 was considered statistically significant. All tests were twosided. Statistical analysis was performed using the Statistical Package for Social Sciences (SPSS, Version 25; SPSS, Inc., Armonk, NY, USA).

\section{Ethics}

All patients provided informed written or verbal consent when the survey was completed by mail or over the phone, respectively. The study received institutional review board approval.

\section{Results}

A total of 392 eligible patients were identified from the database, of which 147 (38\%) were contactable and responded to the questionnaire. Forty-seven respondents (32\%) were female (Fig. 1). There was no difference in baseline characteristics, preoperative risk factors, operative factors, postoperative factors, or time to contact after surgery between patients underwent LAR, CAA, and APR-Table 1.

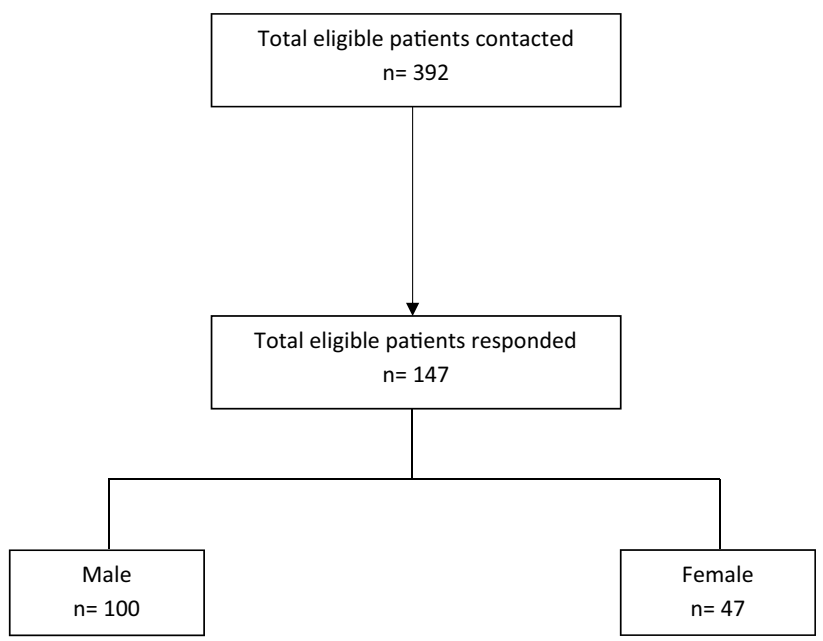

Fig. 1 Study flow diagram 
Table 1 Demographic and baseline characteristics

\begin{tabular}{|c|c|c|c|c|}
\hline \multirow[t]{2}{*}{ Characteristics } & \multicolumn{3}{|l|}{ Operation } & \multirow[t]{2}{*}{ Total } \\
\hline & LAR & CAA & APR & \\
\hline Participants, $n$ & 40 & 66 & 41 & 147 \\
\hline Median age (IQR), years & $64(55-71)$ & $51(45-64)$ & $61(55-72)$ & $59(50-67)$ \\
\hline Male, $\%$ & 65 & 70 & 68 & 68 \\
\hline \multicolumn{5}{|l|}{ Preoperative } \\
\hline Median BMI (IQR), kg/m² & $29(24-32)$ & $27(24-31)$ & $26(24-31)$ & $28(24-31)$ \\
\hline Smoking, $\%$ & 13 & 14 & 15 & 14 \\
\hline ASA III or IV, \% & 20 & 18 & 17 & 18 \\
\hline Charlson score $>3, \%$ & 15 & 10 & 7 & 11 \\
\hline Preoperative obstructive urinary symptoms, $\%$ & 30 & 14 & 15 & 18 \\
\hline Prior abdominal surgery, $\%$ & 43 & 29 & 32 & 33 \\
\hline Clinical stage AJCC III, \% & 50 & 41 & 56 & 48 \\
\hline Neoadjuvant radiotherapy, $\%$ & 53 & 65 & 66 & 62 \\
\hline \multicolumn{5}{|l|}{ Operative } \\
\hline MIS, \% & 85 & 89 & 51 & 78 \\
\hline Other concurrent resection, $\%$ & 8 & 9 & 16 & 11 \\
\hline Median operation time (IQR), min & $270(223-356)$ & $269(236-354)$ & $282(239-358)$ & $270(233-355)$ \\
\hline \multicolumn{5}{|l|}{ Postoperative } \\
\hline Readmission, $\%$ & 15 & 22 & 13 & 17 \\
\hline Anastomotic leak or intra-abdominal abscess, $\%$ & 13 & 9 & 3 & 8 \\
\hline Complication grade III or IV, \% & 3 & 6 & 8 & 5 \\
\hline Adjutant chemotherapy, $\%$ & 47 & 68 & 58 & 59 \\
\hline Back to same job, $\%$ & 82 & 90 & 78 & 84 \\
\hline \multicolumn{5}{|l|}{ Questionnaire } \\
\hline Median time to contact after surgery (IQR), months & $39(27-46)$ & $38(24-51)$ & $37(22-46)$ & $38(25-49)$ \\
\hline
\end{tabular}

AJCC American Joint Committee on Cancer, APR abdominoperineal resection, ASA American Society of Anesthesiologists, $B M I$ body mass index, $C A A$ colo-anal anastomosis, $I Q R$ interquartile range, $L A R$ low anterior resection, $M I S$ minimally invasive surgery

Table 2 Overall sexual dysfunction by gender and operation

\begin{tabular}{llllrl}
\hline & \multicolumn{2}{l}{ Operation } & Total & $p$ value \\
\cline { 2 - 4 } & LAR & CAA & APR & & \\
\hline Participants, $n$ & 40 & 66 & 41 & 147 & \\
Overall, $\%$ & 78 & 67 & 68 & 70 & 0.48 \\
Male, $\%$ & 73 & 54 & 64 & 62 & 0.27 \\
Female, $\%$ & 86 & 95 & 77 & 87 & 0.30 \\
\hline
\end{tabular}

$A P R$ abdominoperineal resection, $C A A$ colo-anal anastomosis, $L A R$ low anterior resection

The overall sexual dysfunction rate was $70 \%$ at a median time from surgery of 38 months. Sixty-two men $(62 \%)$ and 41 women $(87 \%)$ reported overall scores that fell below one standard deviation of the population mean. There was no significant difference in sexual dysfunction for both male and female patients between LAR, CAA, or APR $(78 \%, 67 \%$, and $68 \%$ respectively)-Table 2.

The most common problem for men was erectile dysfunction (62\%), followed by sexual desire (40\%). The most common problem for women was sexual desire (92\%), followed by satisfaction (85\%)-Table 3 .

\section{Discussion}

This study documents the prevalence of sexual dysfunction following surgery for rectal cancer by gender and operation type in our institution, using standardized metrics. The overall rate of sexual dysfunction, defined as less than one standard deviation below the normal control group mean on the validated IIEF or FSFI scores, was 70\%. There was no significant difference in reported sexual dysfunction by type of operation.

Traa et al. highlighted the importance of delineating sexual dysfunction and quality of sexual life in their systematic review [5]. Sexual dysfunction refers to the biological aspects such as the ability to reach orgasm, whereas quality of sexual life takes into account one's own evaluation of sexual function. The IIEF and FSFI validated tools used in this study cover both. Although a negative impact on sexual 
Table 3 Percent of patients reporting dysfunction in each domain as defined by less than one standard deviation below population mean

\begin{tabular}{|c|c|c|c|c|}
\hline & Open $n=33$ & MIS $n=114$ & Total $n=147$ & $p$ value \\
\hline Sexual dysfunction, $n(\%)$ & $25(75.8 \%)$ & $78(68.4 \%)$ & $103(70.1 \%)$ & 0.519 \\
\hline Total number of males, $n$ & 27 & 73 & 100 & \\
\hline Male sexual dysfunction (IIEF), $n(\%)$ & $19(70.4 \%)$ & $43(58.9 \%)$ & $62(62.0 \%)$ & 0.357 \\
\hline Erectile function, $($ score $<18.2), n \%)$ & $19(70.4 \%)$ & $43(58.9 \%)$ & $62(62.0 \%)$ & 0.357 \\
\hline Orgasmic function, (score $<5.9), n(\%)$ & $8(29.6 \%)$ & $8(11.0 \%)$ & $16(16.0 \%)$ & 0.033 \\
\hline Sexual desire, $($ score $<5.2), n(\%)$ & $13(48.1 \%)$ & $27(37.0 \%)$ & $40(40.0 \%)$ & 0.362 \\
\hline Intercourse satisfaction, $($ score $<6.7), n(\%)$ & $5(18.5 \%)$ & $4(5.5 \%)$ & $9(9.0 \%)$ & 0.057 \\
\hline Overall satisfaction, (score <6.9), $n(\%)$ & $17(63.0 \%)$ & $39(53.4 \%)$ & $56(56.0 \%)$ & 0.497 \\
\hline Total number of females, $n$ & 6 & 41 & 47 & \\
\hline \multicolumn{5}{|l|}{ Female sexual dysfunction (FSFI) } \\
\hline Desire, $($ score $<5.01), n(\%)$ & $5(83.3 \%)$ & $38(92.7 \%)$ & $43(91.5 \%)$ & 0.432 \\
\hline Arousal, (score < 13.18), $n(\%)$ & $5(83.3 \%)$ & $21(51.2 \%)$ & $26(55.3 \%)$ & 0.204 \\
\hline Lubrication, (score < 15.43), $n(\%)$ & $5(83.3 \%)$ & $20(48.8 \%)$ & $25(53.2 \%)$ & 0.194 \\
\hline Orgasm, $($ score $<9.54), n(\%)$ & $5(83.3 \%)$ & $19(46.3 \%)$ & $24(51.1 \%)$ & 0.188 \\
\hline Satisfaction, (score <9.77), $n(\%)$ & $6(100.0 \%)$ & $34(82.9 \%)$ & $40(85.1 \%)$ & 0.571 \\
\hline Pain, $($ score < 11.11), $n(\%)$ & $3(50 \%)$ & $18(43.9 \%)$ & $21(44.7 \%)$ & $>0.99$ \\
\hline
\end{tabular}

Total number of males 100 and total number of females 47

FSFI female sexual function index, IIEF international index of erectile dysfunction, MIS minimally invasive surgery desire was observed across both genders, it was more striking in female patients with $92 \%$ reporting a sexual desire score that fell less than one standard deviation below the normal control mean. Arousal was also commonly affected $(55 \%)$. It is, therefore, not only important to better understand the impact of surgical intervention, but also the psychosocial factors that may impact sexual function. Surgeons need to be cognizant of the impact of surgery for rectal cancer on sexual function and quality of sexual life.

Although overall rate of sexual dysfunction in our study was high it is inline with previously reported studies [5]. It is worth noting that our study did not discriminate as to whether a respondent was sexually active or not before surgery, which may have increased our rate. Most (87\%) women reported sexual dysfunction, a consequence of surgery often neglected by surgeons and researchers [8-10]. This has often been attributed to a reluctance of patients to respond to questions about their sexual function [8-10], however, although not quantified, the impact of surgery on female sexual function is not commonly discussed. These high rates of sexual dysfunction highlight the need to discuss such outcomes with both male and female patients in the perioperative period and refer to specialists when appropriate.

The lack of difference in reporting of sexual dysfunction by type of operation differs from previous reports noting patients who undergo APR report more sexual dysfunction than those who undergo LAR [5, 11-15]. This may be reflective of a type II error; however, these studies all focused on one gender or did not use validated tools specific to sexual dysfunction. This certainly warrants further investigation.
Our study has several limitations. Although the number of patients in our cohort was high in comparison to other studies, our response rate was just under forty percent. This might indirectly carry a risk of selection bias. Some patients were reluctant to partake, perhaps because of a lack of wanting to share details on a sensitive topic, though this was not recorded. We did not collect baseline sexual function data, so scores were compared against non-matched population means. Although the median time of interrogation was 38 months and likely suggestive of long term function, our metrics were taken at a single point in time.

This study adds to the growing body of literature on sexual function after rectal cancer surgery. Importantly, it serves as a reminder to surgeons and their teams to openly discuss the impact of surgery on sexual function and ensure adequate consent and appropriate post-operative management strategies. Further studies might focus on a prospective design with baseline data and multiple points of follow-up post-surgery.

Funding This research did not receive any specific grant from funding agencies in the public, commercial, or non-profit sectors. This original study has not been published, presented, or submitted to any other journal.

\section{Declarations}

Conflict of interest Authors have no conflict of interest to disclose. 


\section{References}

1. Siegel RL, Miller KD, Jemal A (2019) Cancer statistics, 2019. CA Cancer J Clin 69:7-34

2. Hassan I, Cima RR (2007) Quality of life after rectal resection and multimodality therapy. J Surg Oncol 96:684-692

3. Bloom JR, Petersen DM, Kang SH (2007) Multi-dimensional quality of life among long-term (5+ years) adult cancer survivors. Psychooncology 16:691-706

4. Keating JP (2004) Sexual function after rectal excision. ANZ J Surg 74:248-259

5. Traa MJ, De Vries J, Roukema JA, Den Oudsten BL (2012) Sexual (dys)function and the quality of sexual life in patients with colorectal cancer: a systematic review. Ann Oncol 23(1):19-27

6. Rosen R, Brown C, Heiman J, Leiblum S, Meston C, Shabsigh R, Ferguson D, D’Agostino R (2000) The Female Sexual Function Index (FSFI): a multidimensional self-report instrument for the assessment of female sexual function. J Sex Marital Ther 26(2):191-208

7. Rosen R, Riely A, Wagner G, Osterloh I, Kirkpatrick J, Mishra A (1997) The international index of erectile function (IIEF): a multidimensional scale for assessment of erectile dysfunction. Urology 49(6):822-830

8. Hendren SK, O'Connor BI, Liu M, Asano T, Cohen Z, Swallow CJ, MacRae HM, Gryfe R, McLeod RS (2005) Prevalence of male and female sexual dysfunction is high following surgery for rectal cancer. Ann Surg 242:212-223

9. Havenga K, Enker WE, McDermott K et al (1996) Male and female sexual and urinary function after total mesorectal excision with autonomic nerve preservation for carcinoma of the rectum. J Am Coll Surg 182:495-502

10. Sailer MD, Sebastian E, Fuchs K-H (2000) How useful is the EORTC QLQ- CR38 in the pre- and post-operative evaluation of patients with rectal cancer? QoL Newsl 25:12-13

11. Stamopoulos P, Theodoropoulos GE, Papailiou J et al (2009) Prospective evaluation of sexual function after open and laparoscopic surgery for rectal cancer. Surg Endosc 23(12):2665-2674

12. Tekkis PP, Cornish JA, Remzi FH et al (2009) Measuring sexual and urinary outcomes in women after rectal cancer excision. Dis Colon Rectum 52:46-54

13. Morino M, Parini U, Allaix ME et al (2009) Male sexual and urinary function after laparoscopic total mesorectal excision. Surg Endosc 23:1233-1240

14. Breukink SO, van der Zaag-Loonen HJ, Bouma EM et al (2007) Prospective evaluation of quality of life and sexual functioning after laparoscopic total mesorectal excision. Dis Colon Rectum 50:147-155

15. Chorost MI, Weber TK, Lee RJ et al (2000) Sexual dysfunction, informed consent and multimodality therapy for rectal cancer. Am J Surg 179:271-274

Publisher's Note Springer Nature remains neutral with regard to jurisdictional claims in published maps and institutional affiliations. 